\title{
Comparative Study between Bipolar Electro-Cautery and Knot-Tying Technique in Total Thyroidectomy
}

\author{
Ahmed M. Hegab ${ }^{1, *}$ MD.
}

\author{
* Corresponding Author: \\ Ahmed M. Hegab \\ surghegab@gmail.com
}

Received for publication September 02, 2021; Accepted October 01. 2021; Published online October 01, 2021.

Copyright The Author published by Al-Azhar University, Faculty of Medicine, Cairo, Egypt. Users have the right to read, download, copy, distribute, print, search, or link to the full texts of articles under the following conditions: Creative Commons Attribution-Share Alike 4.0 International Public License (CC BY-SA 4.0).

doi: $10.21608 /$ aimj.2021.91331.1553

${ }^{1}$ General Surgery Department, Faculty of Medicine, Al-Azhar University Cairo, Egypt.

\begin{abstract}
Background: Thyroidectomy could be considered as the commonest neck surgery in surgical practice. Proper thyroidectomy requires careful and meticulous devascularization of the gland with preservation of surrounding important structures. Haemostasis during thyroidectomy achieved by suture ligation, electro-cautery or vessel sealing devices. The traditional knot-tying method requires carful dissection which is time consuming and may lead to injury of laryngeal nerves or impairment of blood supply to parathyroid glands. Bipolar electrocautery has precise delivery of electric current between its tips with no or limited thermal dispersion to surrounding structures. Advanced vessel sealing devices not always available and requires special disposable handles which increases the coast.

Aim of the work: This prospective comparative study aims at evaluating the outcome of thyroidectomy using bipolar in comparison with traditional thyroidectomy using suture ligation.

Patients and methods: Total thyroidectomy was carried out on 60 patients, equally divided in two groups each 30 patients. First group, haemostasis has been achieved by suture ligation. In the second group bipolar electro-cautery has been used.

Results: In group A (knot-tying) mean operative time was $124.7 \pm 5.2$ min and estimated blood loss about $101 \pm 15.9 \mathrm{ml}$ with significant $\mathrm{P}$ value in comparison with group B (bipolar) in which mean operative time was $103.9 \pm 7.8 \mathrm{~min}$ and blood loss about $80 \pm 16.2 \mathrm{ml}$. Significant $\mathrm{P}$ value regarding post-operative pain but non-significant regarding operative and post-operative complications.

Conclusion: Bipolar electro-cautery is a simple and effective in thyroidectomy with less operative time, blood loss and without increased incidence of complications.
\end{abstract}

Keywords: Thyroidectomy; Bipolar; Suturless.

\section{INTRODUCTION}

Successful neck surgery demands proper dissection, good haemostasis, proper exposure and preservation of important and vital structures. Thyroidectomy is the commonest neck surgery in surgical practice with multiple indications for such surgery and also serious adverse effects that may affect patient breathing, voice and life style .

Haemostasis in surgical practice could be achieved by the commonest knot-tying technique, electrocautery and vessel sealing devices .

Knot- tying is the commonest effective haemostatic method in thyroidectomy despite of its adverse effects like increased operative time, suture complications like slipped stitch, excessive tissue reaction with subsequent fibrosis and its effect on the surrounding structures. ${ }^{1}$
Disclosure: The author have no financial interest to declare in was paid for by the author.

Authorship: author Has a substantial contribution to the article. 
requires as low as $5 \%$ of the power needed for monopolar electro-cautery without heat dispersion. ${ }^{3-7}$

This study aims at evaluating efficacy and safety of bipolar electro-cautery for haemostasis in suturless thyroidectomy comparing it with knot-tying technique with special concern to operative time, blood loss, operative and post operative complications.

\section{PATIENTS AND METHODS}

This is prospective comparative study carried out at Al-Azhar university hospital (Cairo) during the period from Jul 2015 to august 2018 in which total thyroidectomy was carried out on 60 patients , all had been indicated for total thyroidectomy and followed up for maximum 6 months post-operative. Patients were divided into two groups each 30 patients. Group (A), thyroidectomy by knot-tying technique while in group (B) bipolar electro-cautery was used.

The following data has been collected and statistically analyzed:

Operative data: operative time, blood loss and complications.

Post-operative data: post-operative pain score, voice changes, hypocalcaemia, wound collection, duration of drain, nature and amount of drained fluid in suction drain.

Inclusion criteria: all cases had been indicated for total thyroidectomy without additional procedure, signed informed consent and attended regular follow up.

\section{Exclusion criteria:}

Patients requiring additional procedures like node dissection, Patient requiring additional operative procedure like muscle cutting to avoid its effect on post-operative data and pain score.

Irregular follow up .

Patient refused participation in the study.

Proper pre-operative evaluation was carried out to all patients including routine blood tests, hormonal assay, radiological imaging, ENT consultation for vocal cord assessment and FNAC in selected cases.

Euthyroid state has been achieved in all patients before surgery. All patients were informed about the procedure, operative, post operative complications and the need for life-long replacement therapy after surgery.

This study was carried out after being approved from ethical committee and consented from all participants.

II. Operative technique:

Total thyroidectomy was carried out in the same standard steps from positioning, incision and exposure of the gland. Careful dissection, exposure, preservation of parathyroid glands and laryngeal nerves. The difference was in devascularization and haemostatic method .

In Group A, devascularization and haemostasis was achieved by the standard knot-tying method. Dissection, selective ligation and division of middle thyroid vein, upper pole and lower pole of thyroid gland using absorpable suture (vicryl 2/0-3/0 .

In Group B: haemostasis by bipolar electro-cautery to all supplying vessels including superior, inferior pedicle, un-named blood vessels and Berry,s ligament. No suture material was used in gland devascularization.

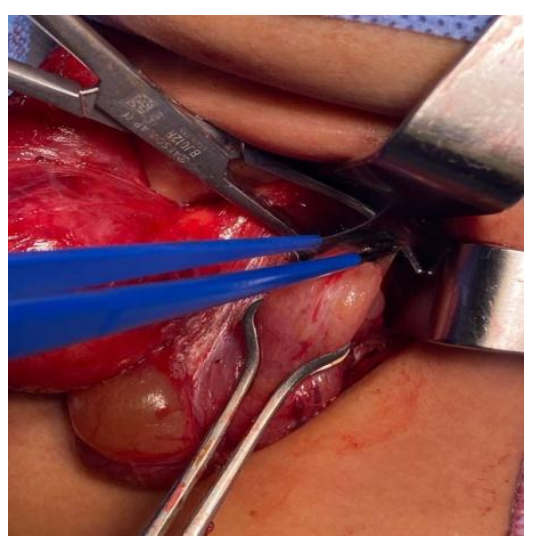

a) Upper pole

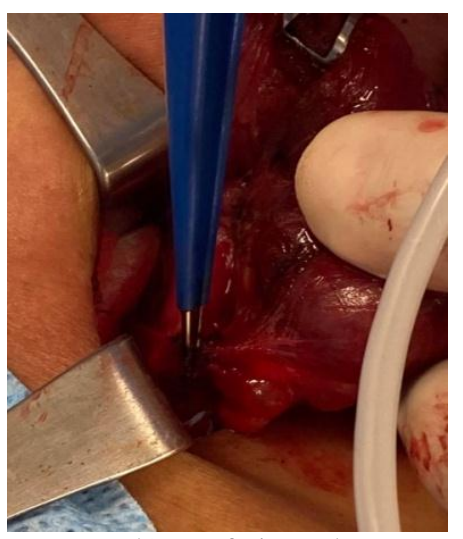

b) Inferior pole

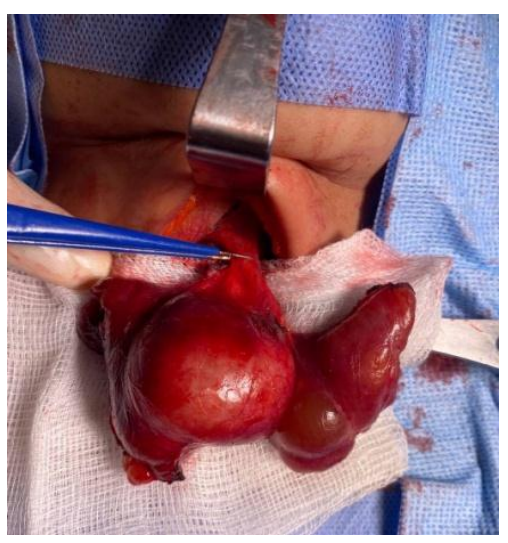

c) Pyramidal lobe

Fig 1: Devascularization of the gland. 


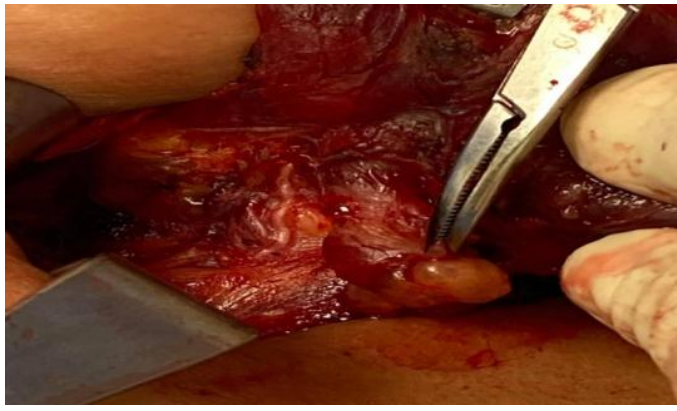

Fig 2: Identification of recurrent laryngeal nerve.

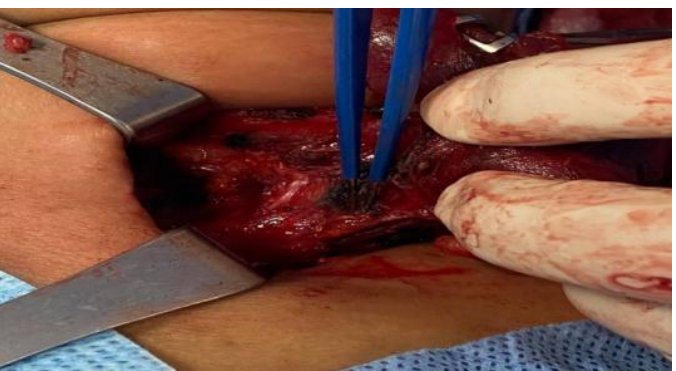

Fig 3: Taking down Berry,s ligament

\section{RESULTS}

This study was carried out at Al-Azhar university hospital on 60 patients all had thyroid diseases indicated for total thyroidectomy. Patients have been divided into 2 equal groups:

Group A (knot-tying group): included 30 patients (3 males and 27 females) with a mean age $44.8 \pm 9.7$ years. Haemostasis was carried out by knot tying technique.

Group B (bipolar group): included 30 patients (4 males and 26 females) with a mean age $44 \pm 8.9$ years. Haemostasis was carried out by bipolar electro-cautery.

Indications for total thyroidectomy in both groups was;

Simple multi-nodular goiter in 43 patients (71.7\%).

Graves disease with non compliance to medication in 5 patients $(8.3 \%)$.

Secondary toxic goiter in 5 patients $(8.3 \%)$.

Nodular goiter on top of thyroiditis in 2 patients $(3.2 \%)$.

Solitary thyroid nodule with suspicious FNA in 5 patients $(8.3 \%)$

Bilateral vocal cord mobility has been confirmed in all patients by pre-operative indirect laryngoscope. Uneventful total thyroidectomy has been carried out to all patients in both groups with no mortality, no permanent complications and no patients required redo surgery.

Statistical analysis of collected operative and postoperative data showed the following results.
At the end, suction drain was inserted at operative bed, anatomical closure using absorpable suture $2 / 0$ $3 / 0$. Subcuticular skin closure by polypropylene $3 / 0$.

Operative and post-operative data had been recorded and statistically analyzed.

III. Post-operative assessment:

All cases had been followed up during hospitalization for:

Pain score using VAS and amount of required analgesia.

Drain: volume, nature of fluid and time of removal.

Wound: hemorrhage, hematoma, seroma and infection.

Hypo-parathyroidism manifested by early hypocalcaemia.

Nerve palsy either to RLN or superior laryngeal nerve.

Duration of hospitalization.

Life-long hormone replacement therapy has been prescribed to all patients and the dose has been adjusted according to laboratory results on outpatient follow up. Regular follow up at 1 week, 1 month, 3 months and 6 months post-operative.

\begin{tabular}{cccc}
\hline & $\begin{array}{c}\text { Group A } \\
\text { (Knot- } \\
\text { tying) }\end{array}$ & $\begin{array}{c}\text { Group B } \\
\text { (Bipolar) }\end{array}$ & P value \\
\hline $\begin{array}{c}\text { Operative time } \\
\text { (minutes) }\end{array}$ & $124.7 \pm 5$ & $103.9 \pm 7.8$ & $<0.001$ \\
$\begin{array}{c}\text { Blood loss (ml) } \\
\text { Pain score }\end{array}$ & $101 \pm 15.9$ & $80 \pm 16.2$ & $<0.001$ \\
$\begin{array}{c}\text { Complications } \\
\text { hypo-calcaemia }\end{array}$ & $\begin{array}{c}4 \text { patients } \\
(13.3 \%)\end{array}$ & $\begin{array}{c}1 \text { patient } \\
(3.3 \%)\end{array}$ & $>0.1$ \\
RLN insult & $\begin{array}{c}1 \text { patient } \\
(3.3 \%)\end{array}$ & $\begin{array}{c}1 \text { patient } \\
(3.3 \%)\end{array}$ & \\
Wound seroma & 2 patients & 2 patients & \\
& $(6.7 \%)$ & $(6.7 \%)$ & \\
Hospital stay & $2.1 \pm 0.8$ & $1.9 \pm 0.5$ & $>0.1$ \\
(days) & & & \\
\hline
\end{tabular}

Table 1: operative and post-operative results.

Significantly reduced operative time in group B than in group A with significant $\mathrm{p}$ value $<0.001$.

Bipolar (suturless) thyroidectomy was associated with less blood loss than ordinary knot-tying technique.

Recorded operative and post-operative morbidity in both groups showed non-significant $\mathrm{P}$ value $(>0.1)$. All complicated cases has been recovered within 6 weeks without permanent effect.

There was significant difference between both group regarding post-operative pain severity with significant $\mathrm{P}$ value $(<0.001)$ has been recorded according to visual analogue scale (VAS).

Despite of reduced post-operative drainage per suction drain in group (B) and early removal of 
suction drain in the first day post-operative, no significant difference in hospital stay.

One patient in knot tying group developed postoperative laryngeal spasm which was attributed to laryngeal odema secondary to repeated trial of difficult intubation with good response to steroids and oxygen therapy with no need for prolonged intubation or ICU admission.

From all patients in both groups, 5 patients only developed post-operative transient hypoparathyroidism. 4 patients diagnosed by laboratory low serum calcium in early post-operative period without hypocalcaemic manifestations. Only one patient developed manifestations of hypocalcemia in the form of circumoral numbness tingling and numbness in both hands. All cases of hypocalcemia were transient with good response to oral $\mathrm{Ca}$ and Vit $\mathrm{D}$ supplementation.

No cases for permanent RLN injury or permanent hypo-parathyroidism were recorded.

\section{DISCUSSION}

Safe and successful surgical procedure necessitates carful dissection with good haemostasis for proper identification and preservation of important structures. Knot-tying technique is the standard haemostatic method in general surgical practice. Vessel sealing devices has been used to save more time but associated with extra coast. ${ }^{8}$

Thyroid gland has been considered to have the richest blood supply, approximately $80 \mathrm{ml} \backslash 100 \mathrm{~g}$ \s. This blood supply doubled in case of hyper thyroidism. ${ }^{9}$

Being one of richest blood supplied organs, improper haemostasis could lead to serious consequences like re-operation, laryngeal nerve damage and devitalization of parathyroid glands. ${ }^{10}$

In general surgical practice, the incidence and type of complications are closely related to type of surgery, surgeon experience, nature of used materials, underlying pathology and other patient's factors. Electro-cautery can safely and effectively seals vessels up to $2 \mathrm{~mm}$, however, lateral thermal dispersion cannot be precisely estimated and prevented. Classic suture haemostasis has been proved be safe and effective but associated with more time, more dissection, retained foreign body at operative site with prolonged tissue reaction, extensive fibrosis with late and scar complications. ${ }^{11}$

In a comparative study, Manouras et al found reduced operative time by about $15-20 \%$ if bipolar or vessel sealer has been used in comparison with classic technique. Longer operative time in other studies has been attributed to learning curve. ${ }^{12}$

Monopolar electro-cautery was safe and effective in achieving haemostasis in thyroidectomy, as reported by Sandonato $\mathrm{L}$ et al, without increased risk of laryngeal nerve injury or hypo-parathyroidism. ${ }^{13}$
However, most surgeons don't prefer its use in thyroidectomy specially near important structures to avoid damage by lateral thermal effect.

In this study, 30 patients underwent total thyroidectomy by conventional knot-tying technique and another 30 patient suturless thyroidectomy has been carried out by bipolar electro-cautery. Patients with other pathologies (retrosternal extension), comorbidities (previous neck surgery) or indicated for another procedure (like neck dissection) that may affect the outcome of surgery was excluded from the study.

In this study, statistically significant reduction in operative time (P-value $<0.001)$ with bipolar electrocautery (103.9 \pm 7.8 minutes) versus conventional knot-tying group (124.7 \pm 5.2 minutes). That result was comparable to other studies reported shortened operative time with use of bipolar electro-cautery or with use of harmonic and ligasure.

Recorded blood lose in bipolar group was also statistically significant ( $\mathrm{P}$ value $<0.001)$ in comparison with conventional group. Athough it was not associated with any clinical effect on the patients ( as blood loss in thyroid surgery is usually minimal to mild ) but matched with other studies conducting that use of electro-cautery and vessel sealing device was associated with less blood lose and better haemostasis.

There was significant difference in pain severity and need for post operative analgesia between both groups ( $\mathrm{P}$ Value $<0.001)$. Bipolar group had less post operative pain $(3.8 \pm 1.2)$ compared to conventional Knot-tying group $(5.8 \pm 0.9)$. Similar study recorded less narcotic analgesia was required in case of bipolar electro-cautery and attributed that to less tissue dissection and absence of residual suture material with subsequent inflammatory tissue reaction. ${ }^{14}$

Per this study the incidence of recurrent laryngeal nerve injury was $3.3 \%$ in bipolar group. Incidence of nerve injury was reported to be $1.85 \%$ by using bipolar electro-cautery in another study carried out by Govindaraj et al. ${ }^{14}$

In this study the incidence of hypoparathyroidism was $3.3 \%$ in bipolar group. Bove et al reported increased incidence of transient hypo-parathyroidism $24.5 \%{ }^{15}$

In this study no recorded cases of reactionary or tertiary haemorrhage. A similar study carried out by Challa et al on 40 patients in whom haemostasis was achieved by bipolar electro-cautery no recorded cases of post operative bleeding. ${ }^{16}$

In this study non significant $\mathrm{P}$ value $(>0.1)$ was observed between both groups regarding hospital stay. Despite of less post operative drainage volume per suction drain and early drain removal in bipolar group, most patients were kept in the hospital till second post operative day for recording and detection of post operative hypocalcaemia which usually occurs in second post operative day. 
Alherabi A et al, reported that bipolar thyroidectomy was associated with less need for drain, less hospital stay and early patient discharge. ${ }^{17}$

Less hospital stay was recorded by Petrakis et al, in case of thyroidectomy by using vessel sealing device $(2.3 \pm 1.7)$ compared to $2.8 \pm 1.3$ days in conventional knot-tying group with significant $\mathrm{P}$ Value $\mathrm{P}<0.001$. However, there was no statistical difference in hospital stay in other studies. ${ }^{18-21}$

Comparative study between bipolar diathermy and other vessel sealing devices, carried out by Challa $S$, Surapaneni $\mathrm{S}$ et al, showd that vessel sealing devices were associated with increased coast and limited use at higher centers only. Bipolar electro-cautery was available at all centers without extra coast and with same efficacy of vessel sealing devices. ${ }^{16}$

In this study, there was no mortality no permanent morbidity in both studied groups.

\section{CONCLUSION}

Suturless thyroidectomy using bipolar electro-cautery was proved to be safe and effective without increased risk of operative, post-operative complications and without increased coast. Bipolar electro-cautery associated with less operative time, less blood loss, less post-operative drainage, decreased pain and may be less hospital stay.

\section{REFERENCES}

1. Vesely DL, Angtuaco EJ Bandoyd CM: Sinus tract in the neck: a rare complication of subtotal thyroidectomy for Graves' disease. $J$ Med. 1986;17(3-4):253-61.

2. Principles of Electrosurgery. Department of Education, Covidien Inc. 2008 http://www.valleylab.com/education/poes/

3. N. S. Williams, C. J. K. Bulstrode and P.R O Connell: Bailey and Love's short practice of surgery, the principles of diathermy, 26th edition. Boca Raton FL CRC Press; 2013;ISBN-13:100:761 .

4. King TT and Worple R: Self-irrigating bipolar diathermy forceps. J Neurosurg. 1972;37:246-7.

5. Dujovny M, Vas R and Osgood CP: Bipolar jeweler's forceps with automatic irrigation for coagulation in microsurgery. Plast Reconstr Surg. 1975;56:585-91

6. Malis LI. Electrosurgery and bipolar technology. Neurosurgery. 2006;58:1-12.

7. James R. Tysome, Rudaina Hassan and Jeremy Davis: Standard bipolar diathermy forceps vessel ligation is safe in thyroidectomy, European Archives of Oto-Rhino-Laryngology. 2009;266, 11, 1781 .

8. Musunuru S, Schaefer S and Chen H: The use of the LigaSure for hemostasis during thyroid
lobectomy.The American Journal of Surgery. 2008; 195:382-5.

9. Hall, John: Guyton and Hall textbook of medical physiology (12th ed.). Philadelphia, Pa.Saunders/Elsevier. p. 907. ISBN 978-1-41604574-8.

10. Massarweh NN, Cosgriff $\mathrm{N}$ and Slakey DP: "Electrosurgery: history, principles, and current and future uses". Journal of the American College of Surgeons. 2006; 202 (3): 520-30.

11. Delik O, Yilmza S, Degirmenci B, et al. The use of a vessel sealing system in thyroid surgery. Acta chir belg. 2005; 105:369-72

12. Manouras A, Markogiannakis $\mathrm{H}$ and Koutras AS: Thyroid surgery: comparison between the electro thermal bipolar vessel sealing system, harmonic scalpel and classic suture ligation. Am J Surg. 2008;195(1):48-52 .

13. Sandonato L, Cipolla C, Graceffa G, et al. Bipolar electro thermic coagulation (ligasure bipolar vessel sealing system) in thyroid surgery. Chir Ital. 2003;55(3):411-5 .

14. Govindaraj E, Meti RM and Ravikiran HR: A study of use of bipolar cautery in thyroidectomy for coagulating vascular pedicles instead of conventional ligation. Inter J Biomed Res. 2015;6(6):382-4 .

15. Bove A, Papanikolaou IG, Bongarzoni G, et al: Thyroid surgery with harmonic focus, ligasure precise and conventional technique:a retrospective case-matched study. Hippokratia. 2012;16(2):154-9.

16. Challa S and Surapaneni S: Suture less thyroidectomy vascular control using bipolar electro thermal cautery, $J$ Evol Med Dent Sci. 2012;1(6):1083-6.

17. Corsten M, Johnson S and Alherabi A; Is suction drainage an effective means of preventing hematoma in thyroid surgery? A meta-analysis. $J$ Otolaryngoly.2005; 34(6):415-7.

18. Petrakis I, Kogerakis N, Lasithiotakis K,et al: Ligasure versus clamp -and-tie thyroidectomy for benign nodular disease. Head and Neck, 2004; 26:903-9.

19. Shen W T, Baumbusch MA, Kebebew E, et al. Use of the electrothermal vessel sealing system versus standard vessel ligation in thyroidectomy. Asian $J$ Surg, 2005; 28:86- 8 .

20. Kirdak T, Korun N and Ozguc H: Use of ligasure in thyroidectomy procedures: result of a prospective comparative study. World J Surg, 2005; 29:771-4.

21. Kiriakopoulos A, Dimitrios T and Dimitrios L: Use of a diathermy system in thyroid surgery. Arch Surg, 2004; 139:997-1000. 